Article

\title{
The Tendency of Urban Stakeholders to Adopt Sustainable Logistics Measures on the Example of a Polish Metropolis
}

\author{
Maria Matusiewicz ${ }^{1, * \mathbb{D}}$, Ryszard Rolbiecki ${ }^{1}$ and Marcin Foltyński ${ }^{2}$ \\ 1 Department of Transport Policy, Faculty of Economics, University of Gdańsk, Sopot 81-824, Poland; \\ ryszard.rolbiecki@ug.edu.pl \\ 2 Institute of Logistics and Warehouse, Poznań, 61-755 Poznań, Poland; marcin.foltynski@ilim.poznan.pl \\ * Correspondence: m.matusiewicz@ug.edu.pl
}

Received: 21 September 2019; Accepted: 21 October 2019; Published: 24 October 2019

check for updates

\begin{abstract}
The scale of policies and measures for sustainable urban freight transport in European cities is still insignificant. However, the situation is changing as more and more cities are adopting sustainable urban logistics plans (SULPs). The situation in cities is extremely heterogeneous, so it would be difficult to point to one single policy that fits all. Yet the tool created with European projects constituting an instruction to prepare SULP allows us to follow the standardized steps, regardless of the conditions found in particular cities. The effectiveness of implementing sustainable measures to a large extent depends on the level of acceptability of individual urban space stakeholders. The article presents the results of a survey conducted among stakeholders of a Polish metropolis-the Gdansk-Gdynia-Sopot metropolitan area. The analysis showed that acceptability rises with the increase in the size of the surveyed entities. The most diversified acceptability ratings were obtained for the transport infrastructure solutions. Proposals for Information and Communication Technologies (ICT) solutions are rated more positively by medium-sized and large enterprises. These solutions are assessed with greater caution by small and micro enterprises. The least diversified and clearly higher acceptance indicators were obtained for proposals in the scope of shaping sustainable urban transport development. The assessments obtained from the respondents should therefore constitute an important element of the works for developing the sustainable urban logistics plans starting in 2020 and also the opinions can be an important element of the future sustainable urban logistics plans, which are currently being developed in many European cities.
\end{abstract}

Keywords: sustainable logistics measures; stakeholders awareness; sustainable urban logistics plan; city stakeholders

\section{Introduction}

The economic importance of urban freight movement cannot be overestimated. In the supply chain, last mile logistics is the least efficient stage and accounts for $28 \%$ of the total delivery cost [1]. Globally, urban freight represents up to $25 \%$ of urban vehicles, takes up to $40 \%$ of motorized road space and contributes to up to $40 \%$ of urban transport-related $\mathrm{CO}_{2}$ emissions [2].

The analysis of the situation in urban logistics in a given area depends on the availability of data on the distribution of goods in the city. Only by knowing the data will it be possible to develop progress in the transport policy concerning the distribution of goods, predict efficiency, determine the impact, assess external costs and improve safety [3].

Since the beginning of the 21st century, many projects supporting urban logistics have been undertaken in Europe. Their aim is to improve the infrastructure, performance or implementation 
of tools to improve the communication of the organizers of goods flows. Urban logistics projects most often aim to reduce the number of individual cars, decrease pollutant emissions in urban spaces, change regulations, e.g., restrictions on driving in urban areas (concerning the size and type of vehicles, hours of entry, charges, exhaust emissions, stopping) or the consolidation of goods in urban mini hubs. However, the introduction of new solutions is impossible without a long-term strategy developed by transport policy makers and the collection of data from the market.

Usually the main objective of city logistics projects is to reduce individual motorization in order to reduce pollutant emissions in urban spaces. These projects concern changes in regulations, changes in the type of vehicles and consolidation centers. In the limited space of a historical city, conceptual change (e.g., cooperation, dock-sharing) may be easier to introduce than hard measures.

As part of an impressive number of initiatives over the past few years, many European cities have embarked on a number of sustainable freight transport projects. The goal of the NOVELOG (New Cooperative Business Models and Guidance for Sustainable City Logistics) project in the years 2015-2018 was to enable cities to implement effective and sustainable policies and to facilitate cooperation between stakeholders in the field of sustainable urban logistics in order to provide knowledge and understanding of urban freight distribution and business travel. The C-LIEGE (Clean Last Mile Transport and Logistics Management) project aimed at the exchange of experience and good practice in the field of city logistics, which covered both soft actions and strategies in the ecological urban freight transport (UFT) sphere, as well as last mile logistics. The SUGAR (Sustainable Urban Goods Logistics achieved by Regional and Local Policies) project focused on addressing the following problems: Firstly, the inefficient and ineffective management of urban freight distribution, secondly the critical component of the general urban transport system and finally the primary source of vehicle pollutant emissions. The URBeLOG (URBan Electronic LOGistics) project aimed to develop and test an innovative, dynamic, open and cooperative e-platform that provides applications and services for the last mile logistics in urban areas. The platform enables to aggregate the stakeholders of transport system and to manage the supply chain in real-time [4]. A detailed review of European projects on city logistics has been prepared by Aditjandra and Zunder [5].

Although comparing the projects at some level is possible [6,7], it is difficult to assess these projects in terms of effects, because each city has different characteristics and conditions of implementation. Additionally, each project tackles a different aspect and offers a different approach. What is more, according to Neirotti et al. the following factors have influence on the adaptation of the project and the attitude of the stakeholders towards it: size and demographic density, economic development, technological development, environmental-friendly policies, other area specific factors like cultural variables, morphological and climatic conditions, political conditions and geographical variables [7]. Many authors $[3,8,9]$ point to the need of defining measures for the evaluation of processes taking place in the city. The available measures also do not fully define the problem-congestion, traffic volume in given hours and $\mathrm{CO}_{2}$ emissions are studied (although there is no unified way to do so either). When analyzing urban freight movement, the most common approaches are: planning, the technological approach, behavioral research and the transport policy. According to the review of the known city logistics modeling by Anand, Quak, van Duin and Tavasszy [10], the most frequently studied subjects are efficiency, environmental impact, more rarely infrastructure, safety and economics.

A comprehensive analysis requires broad and multi-threaded research. The most commonly used descriptors are: traffic flow, commodity flow, pollution level and cost. Less frequently descriptors constitute: land use, location, modal transfer and vehicle loading. Each of the descriptors is examined in each model from a different perspective-planning, behavioral, political and technological. Stakeholders in the city are residents, shippers, administrators and freight carriers [11] but Anand, Quak, van Duin and Tavasszy [10] divide stakeholders into only two groups-public and private ones, noting that their interests (during the common purpose-transporting goods) are contradictory. A similar breakdown is used by K.W. Ogden in the handbook on urban goods movement [12]. 
OECD introduced functional urban area (FUA) to deal with limitations regarding international comparability of densely populated areas linked to administrative boundaries. FUAs are used for highly densely populated municipalities (urban cores). They are also used in case of any adjacent municipalities with a high degree of economic integration with the urban cores. In this case they are measured by travel-to-work flows [13].

Comparing and introducing uniform standards for cities would be possible if unified methodology was introduced. Within the SULPiTER (Sustainable Urban Logistics Planning To Enhance Regional Freight Transport) project, a tool has been designed and developed that aims at estimating the freight demand generated by the economic activities in the FUA individuated by the project partners. SULPiTER tackles urban freight from this territorial perspective. It takes into consideration the functional transport and economic relations between inner urban centers and the surrounding urban territories, as well as the functional transport and economic relations within FUAs not affecting downtowns. The tool consists of a three-step procedure-characterization of the FUA and data collection (1), freight demand and supply modeling (2) and ex-ante evaluation of UFT scenarios (3). The first step, characterization of the FUA, should be done by means of investigation (surveys and traffic counts). This stage gives a dimension to the demand for urban freight transport services, as well to the supply (services, operators and infrastructures) [14].

A sustainable urban logistics plan (SULP) should be considered as an integral part of the sustainable urban mobility plan. It focuses on freight issues within the wider mobility framework. The sustainable urban logistics plan is a useful tool supporting local public decision-makers and stakeholders. It helps them in managing city logistics measures and enhancing freight distribution processes towards economic, social and environmental sustainability, as well as efficiency. The plan involves strategies, measures and rules that can be adopted with a cooperative approach among different actors for reaching common objectives of overall urban sustainability [15]. However, any such initiative must be part of the general municipal mobility strategy. Only one Polish city, Poznan, prepared a SULP (in 2019) and is in the process of proceeding and publishing it. To start working on the preparation of a SULP, it is particularly important to establish partnerships with stakeholders. No effective urban transport policy is possible without prior consultation with transport companies and their organizations, local business groups and residents. A permanent urban freight quality partnership should be created together with all the target groups and the meetings should be held regularly. Conducting reliable research on stakeholder preferences increases the guarantee of the measures being implemented successfully.

In order to fully understand the possibilities for mitigating urban freight flows and to solve the problem holistically, urban freight needs to be tackled on the level of the entire supply chain (including enterprise's strategies) and from the perspective of a given urban area.

Most cities do not hold data on how many trucks are operating within the cities. Neither do they collect information on the origins, destinations, routes of trucks nor on the number of business deliveries made [16]. This lack of data requires significant commitment and awareness on the part of individual entities in the field of shared responsibility for city development. Identification and analysis of other possible measures to be adopted by each area should come as a result of partnership among all city stakeholders. The tendency towards adopting new sustainable logistics measures can be identified through the stakeholders survey [17]. Therefore, the analysis focuses on the nature of the impact of factors conditioning further actions within the discussed area. For the purpose of this study, users of the urban area in the Metropolis were originally divided into the following groups: logistics service providers (LSP); receivers (tenants from the area and administration located in the area) and suppliers (producers and wholesalers). As Aditjandra and Zunder note when developing a 'multi-dimensional poly parametric typology' for city logistics 'one of the major problems in selecting urban freight transport (urban freight) solutions for future implementation, is choosing-from many available options - those that meet the needs of a given city (via key urban freight stakeholder demand), that are compatible with the agreed stakeholder goals'. Research efforts that are meant to engage 
urban freight stakeholders lead to a better understanding of the needs of quality partnerships and as a consequence more effective engagement [5].

In Poland, public awareness of climate change and smog is relatively high. However, at the same time mental biases contribute to low openness towards measures that could tackle these issues. Capitalism in Poland is 30 years old and only now it is beginning to become civilized. Two dominant attitudes in the society are the mistrust towards competition and the belief that the authorities do nothing that could favor entrepreneurs. Hence, the reluctance to establish cooperation on the road in order to increase efficiency and to make decision to use solutions based on cooperation, such as Urban Consolidation Center (UCC) [18].

Many of the supply chain principles and logistics solutions applied today were developed in an era in which sustainability, safety and security were not the most important determinants. Transport, storage and goods handling do not comply with the policy of sustainable development from an economic, environmental and social point of view. Lack of efficiency is visible at every stage-from empty transports to non-utilized distribution centers. Additionally, very often mental barriers or stakeholders' lack of knowledge about the needs of other actors of urban space stand in the way of implementing new solutions.

Effective implementation of advanced solutions in urban logistics is to a large extent defined by the level of acceptance of these solutions among different stakeholders of the urban space. However, a certain gap can be observed in research conducted so far as in general this research does not refer to attitudes and expectations of the urban space stakeholders towards different innovative solutions improving logistics in cities in accordance with the rules of sustainable development.

\section{Methodology}

The purpose of the article was to identify the level of inclination of urban space stakeholders to take innovative and sustainable measures, which are meant to increase the efficiency of the urban supply process. The main objective of the survey was to determine the level of interest of the stakeholders in the urban areas of the Metropolitan Area of Gdańsk, Gdynia and Sopotu (pol. Obszar Metropolitalny Gdansk-Gdynia-Sopot; OMG-G-S) in modern solutions for the organization of supplies in the city.

The following assumption was adopted as the research hypothesis: The level of acceptance of the proposed solutions improving the functioning of the urban freight transport in the city depends on the size of the enterprise; medium and large enterprises are more open to adopt new logistics solutions.

The survey was directed to:

1. Tenants of premises in limited accessibility zone (LAZ) in Gdansk- HoReCa (Hotels, Restaurants, Cafes) industry only;

2. Tenants of premises in Gdynia's city center;

3. Tenants of premises in Sopot;

4. Suppliers to all the three areas mentioned above;

5. Authorities of the cities of Gdansk, Gdynia and Sopot.

Since there was no database of tenants in the studied areas, all the premises in a given area were registered with the use of the observation method, then the contact details were searched for and an invitation was sent to them via e-mail or social media. Inquiries were sent twice to 150 premises located in Gdansk, 100 to tenants from Gdynia and 50 to premises in Sopot. This different number of enquiries sent within the individual cities of the Tricity (Gdańsk, Gdynia and Sopot) agglomeration results from the fact that they vary in terms of the number of inhabitants. At the end of June 2018 the number of inhabitants of individual cities was as follows [19]:

- Gdansk-464,829,

- Gdynia-246,204,

- $\quad$ Sopot-36,328. 
Of the completed questionnaires 30\% were returned (45 questionnaires), of which the majority of respondents $(73.3 \%)$ were small and micro enterprises, which corresponds to the size structure of enterprises in the area. The results have a high cognitive value. Of the respondents $66.6 \%$ represented the HoReCa industry, $24.4 \%$ represented administration, $6.7 \%$ represented suppliers and $2.2 \%$ were manufacturers or wholesalers. The assumption of the research was to analyze the results according to location (Gdansk, Gdynia and Sopot), then according to the group of stakeholders (administration, suppliers, LSP and receivers), according to the business profile (gastronomy, retailers and others) and according to the size of enterprises. However, due to the representation of the received answers mentioned before, a decision was made to analyze the results only according to the size of the enterprise. Since a smaller variation in the number of responses received occurred in the case of stakeholders of the surveyed space classified in terms of size, the analysis of the acceptability level of the promoted solutions was conducted in relation to the stakeholders depending on their size, not location or profile of activity. A breakdown of the institutions surveyed by size is shown in Figure 1.

The structure of surveyed stakeholders

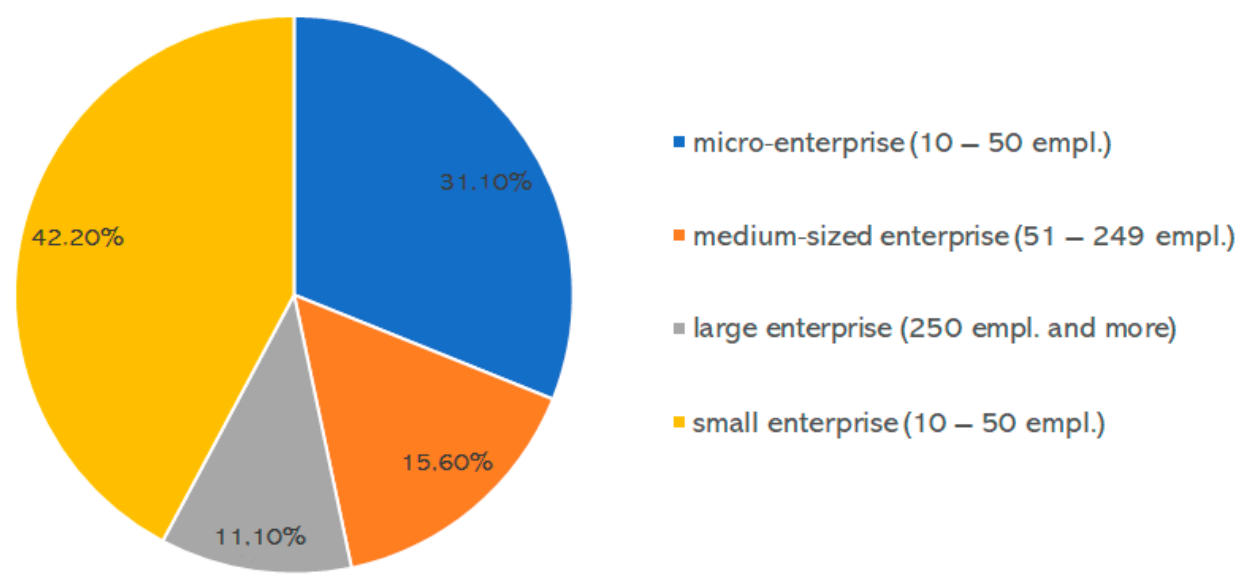

Figure 1. Size of the surveyed institutions in OMG-G-S in terms of employment volume. Source: Own study

The survey was carried out using quantitative data collection techniques. In order to improve the process of survey implementation, a mixed-mode approach was applied, which is based on the interchangeable use of equivalent research techniques. In this case they were:

Computer-assisted telephone interview (CATI)—a telephone interview involving conversations with respondents, using a computer.

Computer-assisted web interview (CAWI) - a quantitative research technique in which the research is conducted with the use of an online questionnaire made available to respondents.

Computer-assisted personal interview (CAPI) — direct interviews in which the interviewer uses a tablet or smartphone to mark the answers given by the respondent on the screen.

The main barrier in conducting the research was the reluctance of stakeholders to participate in the survey. The best informed person was usually the manager who often did not have time. In addition, the stakeholders are often not aware that research results can also be useful in their business. A specialized research company was not employed for the research, we tried to reach the respondents at our own expense.

\section{Characteristics of the Surveyed Area}

In 2014, the President of the city of Gdansk established the limited accessibility zone (LAZ) in the center of Gdansk, which covered the area of 20 ha inside the main town area. LAZ is a kind of Low Emission Zone (LEZ), yet the entry criterion is not the type of vehicle, but the profile of the driver. 
Only the following entities may enter LAZ: residents of real estate located in the zone, owners and tenants of premises, vehicles of cultural, educational and health institutions located in the LAZ area, vehicles of municipal services performing municipal services, press, radio and television. These entities must have a sticker on the vehicle obtained from the city. Access to the limited accessibility zone without an identifier is also valid for guests of the hotels located in the zone. In this case, the inspection authorities must be provided with a valid printed booking. The traffic ban also does not apply to taxis, public transport buses, bicycles and mopeds, official police and city guard vehicles, ambulances and post office cars. In 2018 the sustainable urban mobility plan for Gdansk was published.

Since 2016, the city of Gdynia has had a Sustainable Urban Mobility Plan (SUMP) plan developed with a view to 2025. Gdynia participates in a thematic group on active forms of transport and use of public space. Together with other cities and organizations, it participates in the preparation of European guidelines to ensure that walking and cycling are seen on an equal footing with public transport and cars as means of transport, and not only as a complement to them at the so-called first and last mile of journey.

In the case of Sopot, the issue of distribution of goods is only reflected in the fact that the city manages the transport system, e.g., restrictions on entry to the city and regulations on hours and tonnage.

The OMG-G-S is a local government association established on 15 September 2011 with the aim of strengthening cooperation and harmonious development of the entire metropolitan area around Gdansk, by making the best possible use of the potential of the member cities and municipalities, while respecting their distinctiveness and specificity. Figure 2 shows the boundaries of the metropolitan area.

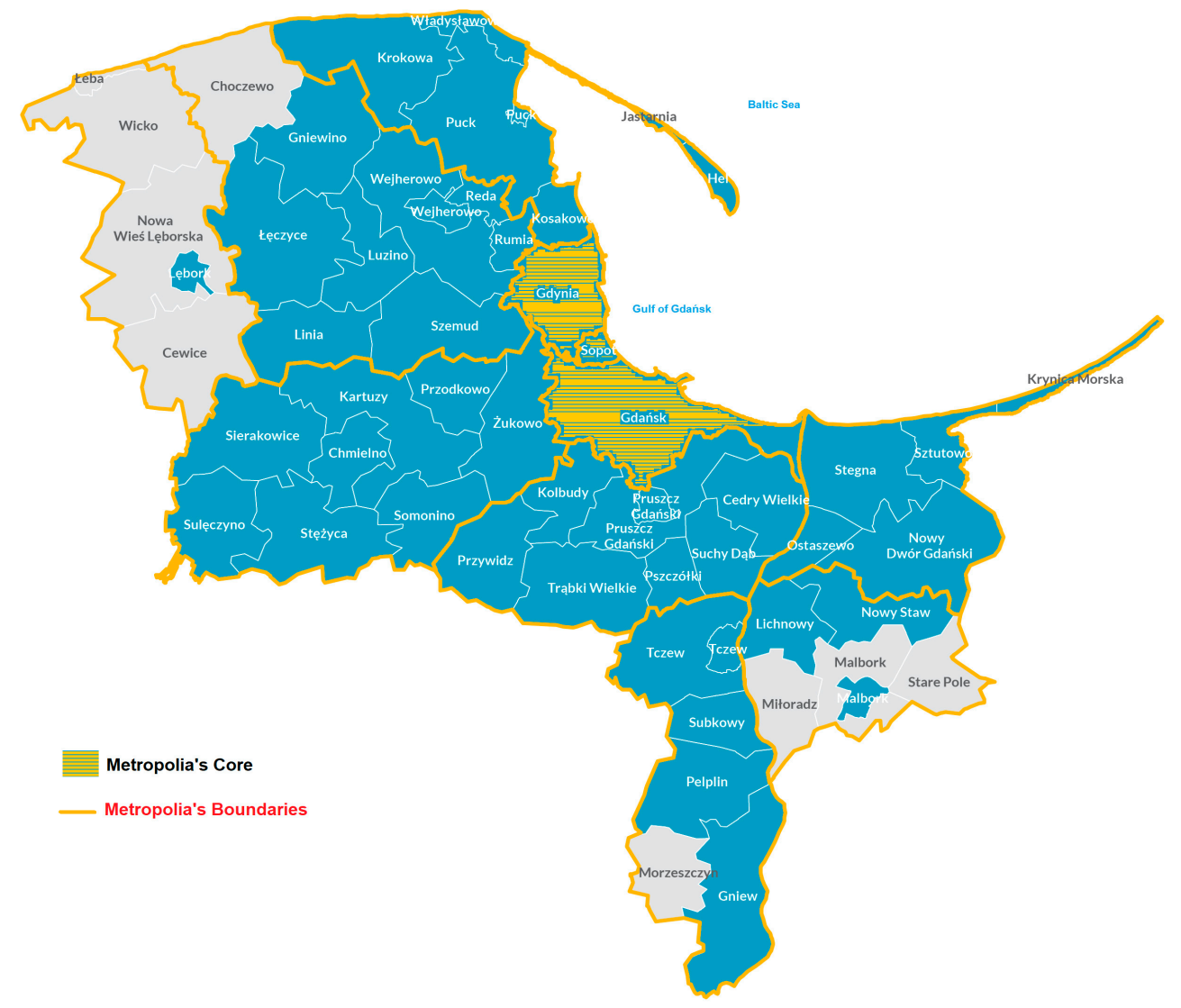

Figure 2. The surveyed area - OMGGS Metropolis. Source: Own work based on [20].

OMG-G-S observations show that mobility of people is perceived by policy makers as the most important part of urban traffic and that distribution of goods in the city is still an underestimated area. In Gdansk and Gdynia, city authorities participate in many smart cities projects, but most of them relate 
to the mobility of people (in Gdansk, e.g., SOHJOA, RUGGEDISED). However, there are few solutions for general traffic management, and even fewer solutions that are dedicated to urban logistics.

Awareness of the importance of efficient urban logistics for the city's development remains low, which is particularly evident in Tricity, as confirmed by research conducted by the author in 2013-2015 [18].

The research was based on the results of the SULPiTER project, in which infrastructural, technological and regulation measures were chosen. The questions were adjusted to the conditions existing in the OMG-G-S. In the research mentioned, the respondents were asked about their attitude towards particular measures. Next, in order to simplify the process of drawing unambiguous conclusions, the graded answers defining the attitude of the respondents were remodeled into remarks to obtain quantitative results. The quantitative research was aimed at the size and scale of some of the phenomena. As a result, it was possible to investigate how often a given phenomenon occurs among the respondents, and the results obtained could be clearly represented in numerical form. An additional advantage of this method was the standardization of measurement tools, which allowed for comparing results obtained from different sources and at different times. The analysis conducted in the article concerns the degree of acceptability of various solutions aimed at shaping sustainable transport in cities (variable Y). The authors did not use the tool for the analysis of qualitative variables, such as logistic regression, due to the lack of detailed questions aimed at obtaining detailed variables (data) characterizing individual groups of economic enterprises (variables X) and failure to fulfill the condition of a sufficiently large number of observations. The methodology proposed was based on a survey conducted in three Polish cities of the Metropolis during the summer of 2018. It took into account the diversity of the analyzed problem—infrastructure, ICT, environment and awareness.

The questions were divided into groups:

Infrastructure and its use:

- Multifunctional lanes, e.g., bus passes;

- Dedicated and planned loading zones;

- Urban Consolidation Centre;

- Cargo tram that uses existing infrastructure (there is a tram line in Gdansk);

- Bus stops used as loading zones.

ICT solutions:

- Other software solutions, e.g., sensory network for parking, smartphones apps used for parking booking, etc.;

- Load-sharing based on UCC and the e-platform;

- Benchmarking (which involves a need for sharing some company information);

- An electronic platform combining transport demand and supply to increase the delivery efficiency and which also requires sharing some company data;

- A system of monitoring the delivery drivers' decisions that supports proper behavior in the city center (e.g., CCTV);

- Metropolis intelligent transport system (ITS) System 'Tristar' used for urban freight transport (UFT), e.g., CCTV cameras recognizing the license plates of the delivery cars, automatically charging for the entrance to the LEZ;

- Interactive city map with the live information about the traffic and available parking spots.

Other sustainable solutions for UFT popular in Europe:

- $\quad$ Night deliveries;

- Last mile deliveries operated by eco vehicles (EVs, Compressed Natural Gas - CNG, hybrid, hydrogen, cargo bikes and an electric scooter);

- LEZ/ZEZ (Zero Emission Zone); 
- Pilot project using the latest technologies for UFT for testing their potential use (delivery drones and autonomic cars);

- Inevitability of financial fines for unauthorized entry to LEZ/ZEZ;

- Inevitability of financial fines for parking of delivery vehicles in prohibited places.

Considering the fact that the sample of respondents was not big enough to differentiate individual groups as the number of representatives was not equal in each of them, we should look at the results through the prism of the enterprise size.

\section{Analysis of Survey Results}

\subsection{Synthetic Presentation of the Research Material Received.}

The structure of the answers to each question in the survey is presented in Table 1. On the basis of these data, it is only possible to make conclusions on the participation of respondents indicating the pre-defined variants of the assessment of particular proposals, improving the flow of goods in the urban space of the Gdansk-Gdynia-Sopot Metropolitan Area. However, it is difficult to assess the degree of acceptability (preferences) of the proposed solutions by the respondents solely on the basis of these results.

For this reason, an in-depth analysis of the answers to individual questions was carried out, using the synthetic variable-weighted average of assessments, which is the measure of the level of acceptability of individual proposals.

To this end, each response variant was assigned a number-specified weight, assuming that the higher the weight, the higher the acceptability of the proposal. These weights were defined as follows:

- 0 -bad proposal,

- 1-rather bad proposal,

- 2-rather good proposal,

- 3-good proposal.

The authors did not suggest the neutral value of weight, as they were afraid that the neutral answer would dominate within the respondents, whom it was already difficult to convince to participate in the research. Grading the weight in even numbers, forces the respondent to give the issue a deeper thought and provide an unambiguous decision.

The weighted response index for each question was calculated according to the following formula:

$$
\text { score }=\frac{\sum_{\mathrm{i}=1}^{\mathrm{m}} \mathrm{w}_{\mathrm{i}} \mathrm{xn}_{\mathrm{i}}}{\mathrm{N}}
$$

where:

wi-weight for response variant $\mathrm{m}$,

$\mathrm{ni}-$ number of responses to a given response variant,

$\mathrm{N}$ - total number of responses to a given question.

This index ranges from 0 to 3, where level 0 means that the solution is not accepted by the respondents (bad proposal) and level 3 is a good solution. Since these are extreme values, it is assumed in advance that if the index is within a range:

from 0.00 to 0.74 - this solution should be assessed as negative,

from 0.75 to 01.49 - this solution should be treated as rather unsuitable,

from 1.50 to 2.24 - this solution is rather good,

from 2.25 to 3.00 - this solution is assessed as good. 
Table 1. Respondents' response structure in terms of willingness to take action to increase the efficiency of supply in the urban space of the Gdansk-Gdynia-Sopot metropolitan area (\%).

\begin{tabular}{|c|c|c|c|c|}
\hline Categories & $\begin{array}{l}\text { Accepted } \\
\text { Solution }\end{array}$ & $\begin{array}{l}\text { Somewhat } \\
\text { Accepted } \\
\text { Solution }\end{array}$ & $\begin{array}{l}\text { Barely } \\
\text { Accepted } \\
\text { Solution }\end{array}$ & $\begin{array}{l}\text { Not } \\
\text { Accepted } \\
\text { Solution }\end{array}$ \\
\hline \multicolumn{5}{|c|}{ Infrastructure and Its Use } \\
\hline Multifunctional lanes, e.g., bus passes & 46.67 & 31.11 & 17.78 & 4.44 \\
\hline Dedicated and planned loading zones & 55.56 & 28.89 & 8.89 & 6.66 \\
\hline Urban Consolidation Centers (mini hubs) & 26.67 & 24.44 & 20.00 & 28.89 \\
\hline Cargo tram that uses existing infrastructure (tram in Gdansk) & 22.22 & 20.00 & 17.78 & 40.00 \\
\hline Bus stops used as loading zones & 15.56 & 24.44 & 15.56 & 44.44 \\
\hline \multicolumn{5}{|c|}{ ICT Solutions } \\
\hline $\begin{array}{l}\text { ICT (e.g., sensory network for parking management, } \\
\text { smartphone apps for booking, etc.) }\end{array}$ & 44.44 & 31.11 & 6.67 & 17.78 \\
\hline Load-sharing based on consolidation and e-platform & 51.11 & 15.56 & 13.33 & 20.00 \\
\hline Benchmarking & 35.56 & 35.56 & 13.33 & 15.55 \\
\hline $\begin{array}{l}\text { An electronic platform with the possibility of connecting to it, } \\
\text { combining the demand and supply of transport services in the } \\
\text { city, in order to increase the efficiency of deliveries. The } \\
\text { technique requires sharing some company data }\end{array}$ & 31.11 & 44.44 & 8.89 & 15.56 \\
\hline $\begin{array}{l}\text { A system monitoring the decisions of delivery drivers that } \\
\text { supports proper behavior in the city center (e.g., CCTV) }\end{array}$ & 48.89 & 26.67 & 15.56 & 8.88 \\
\hline $\begin{array}{l}\text { Interactive city map for suppliers with the live info about the } \\
\text { traffic and parking space }\end{array}$ & 82.22 & 11.11 & 4.44 & 2.23 \\
\hline $\begin{array}{l}\text { 'TRISTAR' (ITS system for OMGGS) operating UFT (e.g., } \\
\text { cameras recognizing the license plate of a delivery car, } \\
\text { automatically charging for entry to the historic zone) }\end{array}$ & 42.22 & 13.33 & 13.33 & 3.12 \\
\hline \multicolumn{5}{|c|}{ Other Sustainable Solutions for UFM } \\
\hline Night deliveries & 57.78 & 15.56 & 13.33 & 13.33 \\
\hline $\begin{array}{l}\text { Last mile deliveries operated by eco-vehicles (electric, CNG, } \\
\text { hybrid, hydrogen, cargo bikes and electric scooter) }\end{array}$ & 53.33 & 20.00 & 6.67 & 20.00 \\
\hline Low emission zone/zero emission zone & 44.44 & 17.78 & 20.00 & 17.78 \\
\hline $\begin{array}{l}\text { Pilot projects using latest technologies for UFT (drones, } \\
\text { autonomic cars) for testing their potential use for the region }\end{array}$ & 44.44 & 28.89 & 11.11 & 15.56 \\
\hline $\begin{array}{l}\text { Inevitability of financial fines for unauthorized entry to } \\
\text { designated separate zones }\end{array}$ & 44.44 & 20.00 & 20.00 & 15.56 \\
\hline $\begin{array}{l}\text { Inevitability of financial fines for parking delivery vehicles in } \\
\text { prohibited places }\end{array}$ & 48.89 & 17.78 & 15.56 & 17.77 \\
\hline
\end{tabular}

Source: own study compiled on the basis of a questionnaire survey.

Synthetic response indices (score) and the share of the responses to the proposals, which according to the respondents were considered good, broken down by the size groups of enterprises, are presented in Tables 2-4. The analysis of these results, according to the layout of these tables, was carried out:

-vertically,

-horizontally.

Vertical analysis aims at assessing the degree of acceptability (attractiveness) of particular solutions within the given size group of enterprises (respondents). The aim of the study is therefore to indicate which of the proposed solutions is the most acceptable and which is the least acceptable in the given group of respondents. Horizontal analysis aims at identifying the level of acceptability of each of the proposed solutions separately by individual size groups of enterprises. The aim of this study is therefore to indicate which entities accept a given proposal to the most extent and which ones accept it to the least. 
Table 2. Share of responses recognizing a given proposal as good and synthetic response indicators for proposed infrastructure solutions in the urban space of the Gdansk-Gdynia-Sopot metropolitan area.

\begin{tabular}{|c|c|c|c|c|c|c|c|c|c|c|}
\hline \multirow[b]{2}{*}{ Question to Respondents } & \multicolumn{2}{|c|}{ General Response } & \multicolumn{2}{|c|}{$\begin{array}{c}\text { Micro-Enterprises } \\
\text { (14 resp.) }\end{array}$} & \multicolumn{2}{|c|}{$\begin{array}{c}\text { Small Enterprises } \\
\text { (19 resp.) }\end{array}$} & \multicolumn{2}{|c|}{$\begin{array}{c}\text { Medium-Sized } \\
\text { Enterprises ( } 7 \text { resp.) }\end{array}$} & \multicolumn{2}{|c|}{$\begin{array}{c}\text { Large Enterprises } \\
\text { (5 resp.) }\end{array}$} \\
\hline & $\begin{array}{c}\text { Accepted } \\
\text { Solution } \\
(0-100)\end{array}$ & $\begin{array}{l}\text { Score } \\
(0-3)\end{array}$ & $\begin{array}{c}\text { Accepted } \\
\text { Solution } \\
(0-100)\end{array}$ & $\begin{array}{l}\text { Score } \\
(0-3)\end{array}$ & $\begin{array}{c}\text { Accepted } \\
\text { Solution } \\
(0-100)\end{array}$ & $\begin{array}{l}\text { Score } \\
(0-3)\end{array}$ & $\begin{array}{c}\text { Accepted } \\
\text { Solution } \\
(0-100)\end{array}$ & $\begin{array}{l}\text { Score } \\
(0-3)\end{array}$ & $\begin{array}{c}\text { Accepted } \\
\text { Solution } \\
(0-100)\end{array}$ & $\begin{array}{l}\text { Score } \\
(0-3)\end{array}$ \\
\hline Multifunctional lanes, e.g., bus passes & 46.67 & 2.20 & 42.80 & 2.14 & 57.89 & 2.42 & 28.57 & 1.71 & 40.00 & 2.20 \\
\hline Dedicated and planned loading zones & 55.56 & 2.33 & 42.84 & 2.00 & 63.16 & 2.53 & 71.43 & 2.57 & 40.00 & 2.20 \\
\hline Urban Consolidation Centers (mini hubs) & 26.67 & 1.49 & 42.84 & 1.79 & 21.05 & 1.26 & 14.29 & 1.29 & 20.00 & 1.80 \\
\hline Cargo tram that uses existing infrastructure (tram in Gdansk) & 22.22 & 1.24 & 21.43 & 1.14 & 15.79 & 1.21 & 28.57 & 1.14 & 40.00 & 1.80 \\
\hline Bus stops used as loading zones & 15.56 & 1.11 & 7.14 & 0.93 & 15.79 & 1.16 & 28.57 & 1.14 & 20.00 & 1.40 \\
\hline
\end{tabular}

Source: own study compiled on the basis of a questionnaire survey.

Table 3. Share of responses recognizing a given proposal as good and synthetic response indicators for solutions using ICT systems in the surveyed cities.

\begin{tabular}{|c|c|c|c|c|c|c|c|c|c|c|}
\hline \multirow[b]{2}{*}{ ICT Solutions-Questions } & \multicolumn{2}{|c|}{ General Response } & \multicolumn{2}{|c|}{$\begin{array}{l}\text { Micro-Enterprises } \\
\text { (14 resp.) }\end{array}$} & \multicolumn{2}{|c|}{$\begin{array}{l}\text { Small Enterprises } \\
\quad(19 \text { resp.) }\end{array}$} & \multicolumn{2}{|c|}{$\begin{array}{c}\text { Medium-Sized } \\
\text { Enterprises }(7 \text { resp.) }\end{array}$} & \multicolumn{2}{|c|}{$\begin{array}{l}\text { Large Enterprises } \\
\text { (5 resp.) }\end{array}$} \\
\hline & $\begin{array}{l}\text { Accepted } \\
\text { Solution } \\
(0-100)\end{array}$ & $\begin{array}{l}\text { Score } \\
(0-3)\end{array}$ & $\begin{array}{l}\text { Accepted } \\
\text { Solution } \\
(0-100)\end{array}$ & $\begin{array}{l}\text { Score } \\
(0-3)\end{array}$ & $\begin{array}{c}\text { Accepted } \\
\text { Solution } \\
(0-100)\end{array}$ & $\begin{array}{l}\text { Score } \\
(0-3)\end{array}$ & $\begin{array}{l}\text { Accepted } \\
\text { Solution } \\
(0-100)\end{array}$ & $\begin{array}{l}\text { Score } \\
(0-3)\end{array}$ & $\begin{array}{c}\text { Accepted } \\
\text { Solution } \\
(0-100)\end{array}$ & $\begin{array}{l}\text { Score } \\
(0-3)\end{array}$ \\
\hline $\begin{array}{l}\text { ICT (e.g., sensory network for parking management, smartphone apps } \\
\text { for booking, etc.) }\end{array}$ & 44.44 & 2.02 & 28.60 & 1.79 & 47.37 & 2.11 & 71.43 & 2.43 & 40.00 & 1.80 \\
\hline Load-sharing based on consolidation and e-platform & 51.11 & 1.98 & 35.71 & 1.43 & 47.37 & 2.05 & 71.43 & 2.29 & 80.00 & 2.80 \\
\hline Benchmarking & 35.56 & 1.91 & 28.57 & 1.79 & 31.58 & 1.79 & 57.14 & 2.57 & 40.00 & 1.80 \\
\hline $\begin{array}{l}\text { Interactive city map for suppliers with the live info about the traffic } \\
\text { and parking space }\end{array}$ & 82.22 & 2.73 & 71.43 & 2.64 & 78.95 & 2.63 & 100.0 & 3.00 & 100.0 & 3.00 \\
\hline $\begin{array}{l}\text { 'Tristar' (ITS for OMGGS) operating UFT (e.g., cameras recognizing } \\
\text { license plate of a delivery car, automatically charging for the entry to } \\
\text { the historic zone) }\end{array}$ & 42.22 & 1.67 & 28.57 & 1.21 & 42.11 & 1.84 & 42.86 & 1.43 & 80.00 & 2.60 \\
\hline
\end{tabular}


Table 4. Share of responses recognizing a given proposal as good and synthetic response indicators for other sustainable urban transport solutions popular in Europe.

\begin{tabular}{|c|c|c|c|c|c|c|c|c|c|c|}
\hline \multirow[b]{2}{*}{$\begin{array}{l}\text { Other Popular Sustainable } \\
\text { Solutions-Questions }\end{array}$} & \multicolumn{2}{|c|}{ General Response } & \multicolumn{2}{|c|}{$\begin{array}{l}\text { Micro-Enterprises } \\
\text { (14 resp.) }\end{array}$} & \multicolumn{2}{|c|}{$\begin{array}{l}\text { Small Enterprises } \\
\text { (19 resp.) }\end{array}$} & \multicolumn{2}{|c|}{$\begin{array}{c}\text { Medium-Size } \\
\text { Enterprises ( } 7 \text { resp.) }\end{array}$} & \multicolumn{2}{|c|}{$\begin{array}{l}\text { Large Enterprises } \\
\text { (5 resp.) }\end{array}$} \\
\hline & $\begin{array}{c}\text { Accepted } \\
\text { Solution } \\
(0-100)\end{array}$ & $\begin{array}{l}\text { Score } \\
(0-3)\end{array}$ & $\begin{array}{c}\text { Accepted } \\
\text { Solution } \\
(0-100)\end{array}$ & $\begin{array}{l}\text { Score } \\
(0-3)\end{array}$ & $\begin{array}{l}\text { Accepted } \\
\text { Solution } \\
(0-100)\end{array}$ & $\begin{array}{l}\text { Score } \\
(0-3)\end{array}$ & $\begin{array}{l}\text { Accepted } \\
\text { Solution } \\
(0-100)\end{array}$ & $\begin{array}{l}\text { Score } \\
(0-3)\end{array}$ & $\begin{array}{l}\text { Accepted } \\
\text { Solution } \\
(0-100)\end{array}$ & $\begin{array}{l}\text { Score } \\
(0-3)\end{array}$ \\
\hline Night deliveries & 57.78 & 2.18 & 64.28 & 2.29 & 57.89 & 2.16 & 71.43 & 2.29 & 20.00 & 1.80 \\
\hline $\begin{array}{l}\text { Last mile deliveries operated by eco-vehicles } \\
\text { (electric, CNG, hybrid, hydrogen, cargo bikes and } \\
\text { electric scooter) }\end{array}$ & 53.33 & 2.07 & 28.57 & 1.50 & 57.89 & 2.11 & 71.43 & 2.57 & 80.00 & 2.80 \\
\hline Low emission zone/zero emission zone & 44.44 & 1.89 & 35.71 & 1.79 & 36.84 & 1.74 & 57.14 & 2.00 & 80.00 & 2.60 \\
\hline $\begin{array}{l}\text { Pilot projects using latest technologies for UFT } \\
\text { (drones and autonomic cars) for testing their } \\
\text { potential use for the region }\end{array}$ & 44.44 & 2.02 & 50.00 & 2.07 & 31.58 & 1.74 & 57.14 & 2.29 & 60.00 & 2.60 \\
\hline $\begin{array}{l}\text { Inevitability of financial fines for unauthorized } \\
\text { entry to designated separate zones }\end{array}$ & 44.44 & 1.93 & 42.84 & 2.00 & 42.11 & 1.79 & 57.14 & 2.14 & 40.00 & 2.00 \\
\hline $\begin{array}{l}\text { Inevitability of financial fines for parking of } \\
\text { delivery vehicles in prohibited places }\end{array}$ & 48.89 & 1.98 & 35.71 & 1.71 & 47.37 & 1.89 & 57.14 & 2.29 & 80.00 & 2.60 \\
\hline
\end{tabular}

Source: own study compiled on the basis of a questionnaire survey. 


\subsection{Level of Acceptability of Infrastructure Solutions Facilitating Cargo Flow in OMG-G-S}

The vertical analysis of the results of the questionnaire study on infrastructure solutions improving cargo flow in the metropolitan area of Gdansk-Gdynia-Sopot (Table 2) shows that in the group of micro enterprises, the most positively evaluated one is the solution based on the use of multifunctional lanes (score 2.14) and the construction of dedicated bays (dedicated) for loading and unloading of goods (score 2.00).

Among the micro enterprises that took part in the survey, the first proposal was considered as good by $42.8 \%$ of enterprises and the second one by $42.84 \%$. In general, therefore, it can be assumed that according to the previously adopted scale for the synthetic indicator, these solutions have been assessed as rather good.

On the other hand, the most skeptical assessment among the enterprises was given to the use of existing bus stops as loading and unloading zones (score 0.93 ). Only $7.14 \%$ of the enterprises in this group considered this solution to be good. Thus, from a synthetic point of view, the proposal was assessed as rather bad.

A very similar result was also achieved in the group of small enterprises, with the proposal to build bays adapted for loading and unloading of goods achieving a higher level of acceptability than the introduction of multifunctional lanes. The same level of preferences was recorded among medium-sized enterprises. As can be seen in Table 3, the results of the level of acceptability of particular infrastructure solutions improving the flow of goods in the Gdansk-Gdynia-Sopot area in the group of large enterprises are not very diversified. It can be assumed that this was to a large extent due to the fact that a small number of entities in this group took part in the survey.

The horizontal analysis of the results of the survey with regard to infrastructure solutions improving the flow of cargo in the studied cities shows that the proposal to use multifunctional lanes had the highest level of acceptance among small enterprises (score 2.42). In this group of enterprises, the share of responses recognizing this solution as good was $57.9 \%$. This solution was the least preferred by medium-sized enterprises (score 1.71).

The use of dedicated bays for loading and unloading of goods had the highest level of acceptance among medium-sized enterprises (score 2.57). More than $71 \%$ of companies in this size group responded that this was a good solution. However, this proposal was least appreciated by micro enterprises (score 2.00). Still, $42.8 \%$ of companies in this size group indicated that this was a good proposal.

The creation of mini hubs, as cargo consolidation centers, achieved the highest acceptability in the group of large enterprises (score 1.80). This solution turned out to be the least attractive for small enterprises.

The solution of adapting the existing infrastructure to use cargo trams and proposal to use the existing bus stops as loading and unloading zones were the most accepted ones among the large companies. However, such solutions in this group of enterprises were accepted by a relatively small group of enterprises. The cognitive value of these results was therefore very limited.

To sum up, the research shows that the most preferred infrastructure solutions among the respondents were the use of bays for loading and unloading goods and the introduction of multifunctional lanes. Taking into account the synthetic response index (score), these solutions were considered to be at least rather good. The least acceptable solutions were the use of existing bus stops as loading and unloading areas and the use of freight trams and adapting the existing infrastructure for this purpose. On the basis of the previously adopted grading scale for the synthetic indicator, it can be assumed that these proposals were considered to be rather bad.

\subsection{Level of Acceptability of ICT Solutions Enabling the Increase in the Efficiency of Cargo Flows in OMG-G-S}

The vertical analysis of the results of the survey on the level of preferences in the area of information and communication technologies (Table 3) shows that in the group of micro enterprises, the most acceptable solutions included the proposal to use interactive maps (score 2.64) and systems for monitoring decisions taken by drivers/suppliers in a given zone. Taking into account the synthetic 
response index (score 2.00), these two proposals, according to the adopted scale, in the surveyed group of enterprises were therefore considered to be a good and rather good solution respectively. The lowest rating (score 1.21) was obtained by a solution using ITS (in the case of Tricity it is the 'Tristar' system) for distribution of supplies. This solution was assessed as bad by $50 \%$ of the group's respondents. Moreover, in the group of micro enterprises, cargo space sharing based on cargo consolidation and e-platform (score 1.43) were considered to be a rather bad solution.

In the group of small enterprises, as in the case of micro enterprises, the proposal to use interactive maps (score 2.63) and the use of systems for monitoring decisions taken by drivers/suppliers (score 2.21) received the highest acceptance. However, unlike micro enterprises, in small enterprises the share of respondents assessing these solutions as good was much higher and amounted respectively to: $78.95 \%$ and $52.63 \%$. According to the survey, small enterprises were least interested in benchmarking and the use of an electronic platform integrating the demand and supply side.

Nevertheless, taking into account the adopted grading scale for the synthetic index of acceptance of these proposals (score 1.79), these were rather good solutions from the point of view of these enterprises.

As can be seen from Table 3, in the group of medium sized entities, with the exception of the use of ITS (score 1.43), the proposed solutions in the field of ICT use received high marks. Synthetic indicators of acceptability of the proposed solutions in this group of entities clearly exceeded the value of 2.0, which means that these proposals were assessed as more than rather good. The use of an interactive map (score 3.0) was considered to be a fully acceptable proposal. This proposal was supported by all entities in the surveyed size group.

On the other hand, large entities were most willing to use load-sharing solutions based on consolidation and e-platform (score 2.80) and interactive city map for suppliers with live info about the traffic and parking space (score 3.0).

The horizontal analysis shows that the acceptability of individual ICT solutions was the lowest in the group of small entities. This acceptability rises with the increase in the size of the surveyed entities.

\subsection{Level of Acceptability of Other Popular Sustainable Logistics Solutions in OMG-G-S}

The horizontal analysis of the acceptability of the proposed solutions aimed at shaping the sustainable development of transport in the analyzed cities (Table 4) shows that in micro enterprises the solution of organizing night deliveries of goods (score 2.29) received the greatest support. This solution was considered good by almost $65 \%$ of the respondents. The smallest support in this size group of the surveyed companies was given to a proposal to impose the inevitability of penalties for stopping a vehicle in a no parking zone. However, on the basis of the synthetic response index (score 1.71) and in accordance with the adopted grading scale, it can be stated that in the opinion of the entrepreneurs of this group this solution was rather good.

In small enterprises, the proposal for night deliveries also received the greatest support (score of 2.16). This proposal was supported by almost $58 \%$ of the respondents in this group of enterprises. The solutions concerning the introduction of low emission zones (score 1.74) and the use of pilot projects testing the latest technologies in deliveries (score 1.74) were the least accepted ones. Nevertheless, in the opinion of entrepreneurs in this size group, according to the adopted scale of assessments, it can be considered that these solutions are perceived as rather good.

Between medium and large enterprises, the prevailing opinion was that the best proposal is the organization of last mile deliveries. Synthetic response indicators for this proposal were respectively 2.57 and 2.80. It can therefore be assumed that they were assessed as good. The lowest level of acceptance in the group of medium enterprises was achieved by the solution consisting in the introduction of low emission zones (score 2.00), and in the group of large enterprises-the organization of night deliveries (score 1.80).

On the other hand, the horizontal analysis shows that the organization of night deliveries was the only proposal that, in all enterprise size groups (except for large enterprises), achieved the highest average acceptability ratings above 2.00 . 
The lowest support was given to the proposal to introduce low emission zones. In the opinion of the surveyed enterprises, the average ratings for the acceptability of this solution were often even lower than the proposal to introduce the inevitability of penalties for entering a closed zone and stopping in an unauthorized place.

The survey also included open questions allowing the respondents to express their opinions (suggestions) on issues other than those included in the questionnaire form. In the additional answers, the respondents pointed to the following in the first place:

The need to ensure greater accessibility to historic city centers (in the current conditions, drivers are often forced to enter the area at the risk of getting a ticket);

The need to extend the delivery time in the LAZ;

The problem of disturbance of quiet hours as a result of night-time deliveries during the tourist season;

Forcing large fast-moving consumer goods (FMCG) suppliers to deliver at specific times;

Disruptions in the supply of goods to customers located in the Gdansk old town during the Dominican Fair;

Blocking bicycle lanes by commercial vehicles.

\section{Summary of the Study}

Out of the three groups of solutions improving the flow of goods in the Gdansk-Gdynia-Sopot metropolitan area, the most diversified acceptability ratings were obtained for the transport infrastructure solutions. Proposals to use existing bus stops as loading and unloading zones, as well as to adapt existing infrastructure to cargo trams, received the lowest ratings of acceptability of all the proposed solutions in the survey. This phenomenon may result from the fear of disturbing the functioning of passenger transport in the cities and the fact that the tram line is located outside the LAZ.

The analysis shows that proposals for ICT solutions are rated more positively by medium-sized and large enterprises. These solutions are assessed with greater caution by small and micro enterprises.

This phenomenon can be explained by the relatively low adaptation of micro and small enterprises to the requirements related to the use of information and communication technologies. The representative surveys conducted by the Statistics Poland show that in 2017 in the group of small enterprises (excluding financial and insurance activities) only $6.8 \%$ of the enterprises employed ICT specialists. In the case of medium-sized (50 to 249 employees) and large (more than 250 employees) companies, these ratios were much higher and amounted to $29 \%$ and $73.5 \%$ respectively. Moreover, according to the Statistics Poland data, in 2017 only 7.7\% of small enterprises provided their employees with trainings improving skills in the field of ICT. In the case of medium-sized enterprises it was $25 \%$, and in the case of large enterprises-62.8\%. As a result, in the group of small enterprises the electronic exchange of information on supply chain management in 2017 was conducted by only $17.8 \%$ of enterprises, while in the group of medium-sized enterprises this share amounted to $32.2 \%$, and in the group of large enterprises-58.7\% (Statistics Poland, 2018).

The least diversified and clearly higher acceptance indicators were obtained for proposals in the scope of shaping sustainable urban transport development. These may result from the growing environmental awareness of the society. According to the annual research conducted for the Ministry of the Environment, more and more people believe that the condition of the environment depends on individual attitudes. While in 2012, 54\% of Poles believed that the improvement of the environment depends on the activity of each person, in 2018 this percentage increased to $56 \%$. This improvement was especially observed among young people aged 15-19 (from 52\% to 57\%). More and more people also believe that environmental protection can have a positive impact on the country's economic development. Between 2012 and 2018, this indicator increased from 76\% to 84\% [21].

It is worthwhile to mention a similar research conducted in Brazil by Oliveira G. and Oliveira L. To assess the importance of the elements and indicate the stakeholders' desires in relation to supporting public policies for urban freight transport the Likert scale was used. In the research, questions about 
three measures were asked-exclusive lane solution, urban distribution center and overnight delivery solution. Relatively positive attitude was analogous in our research with relation to the following measures: exclusive lanes and night deliveries. However, the Brazilian respondents showed a greater level of acceptance for urban distribution centers [22]. In order to find the cause of these differences, the output conditions of the two researched areas should be analyzed and compared.

\section{Conclusions}

Growing urbanization, limitations resulting from the historical development of some urban districts, traffic problems (including congestion), limited spatial availability and increased environmental pollution make the improvement of goods distribution processes in cities one of the biggest challenges today. The share of e-commerce in retail trade in 2018 is almost $12 \%$, compared to $7.4 \%$ in 2015. It is predicted that by 2021 it will be nearly 20\% (Statista, 2019). In the case of distribution of goods in the city, the transport to the last recipient is analyzed. Transport depends on many parameters (infrastructure, road condition and type of goods delivered) and at the same time affects many aspects (congestion, accessibility and pollution). These costs and effects are also interdependent—greater congestion leads to less efficient distribution of goods and vice versa [10].

The article presented the results of the survey conducted among the stakeholders of the Gdansk-Gdynia-Sopot metropolitan area. The opinions of the respondents obtained in this survey should therefore be an important element of the future sustainable urban logistics plans, which are currently being developed in many European cities and in one Polish city, namely Poznan.

This article was an attempt to broaden the discussion in Poland about the importance of city logistics in the lives of residents and it was also meant to raise awareness of the need to adapt to ICT and digital economy. This will help to identify the factors favoring the implementation of new solutions and initiatives by both the private and public sectors. It may also contribute to the future development of a software tool linking the region's stakeholders, which would be an example of good practice. In the surveyed area, stakeholders/users constitute different groups-municipal authorities, companies with their employees, residents and logistics operators. The city's development has to proceed in accordance with the policy of sustainable development, and thus create conditions for development, which will take into consideration the environment and future generations.

The research results show that the stakeholders in the surveyed area show the same tendency of bigger acceptance towards less engaging and less cost-intensive measures, though the size of the company seemed to impact the awareness level. The same is proven by some European examples [23], which show that cities usually choose soft measures with high impact of savings. It also proves that well selected measures and/or their optimal combinations can substantially decrease energy consumption and the $\mathrm{CO}_{2}$ footprint.

Although there are papers on urban logistics, in Poland [17,18,24-35] this field remains an area where there is still need of research and data to introduce innovative solutions, and above all to broaden awareness that city logistics is no less important than commuters mobility and that these are not separate but mutually dependent areas. There is a need for cooperation between the private and public sector. In a city, it might be difficult to implement private initiatives without the support of local authorities.

The researched metropolis authorities are aware of the need for changes in the organization of supplies, which is confirmed by the OMG-G-S Mobility Strategy [20], in which an attempt was made to designate potential locations for urban consolidation centers serving the Tricity area. However, research carried out in the LAZ area in Gdansk in 2013-2016 [17] showed that the resistance of tenants of ground-store commercially used floors is very high, so the authorities are afraid to take action. As regards the organization of deliveries to the LAZ in the city center, consultations concerning this zone were convened at the end of 2017, but they were not very popular. It should be borne in mind that although the city authorities understand the need for changes necessary for the sustainable 
development of the managed space, they are reluctant to undertake them due to their lack of popularity, which in turn is caused by the lack of public awareness.

The roadmap developed by the SULPiTER project is a tool available for every city to follow systematically. The first step of the roadmap is an attempt to characterize the FUA and collect all the information necessary to represent the urban freight distribution system. The characterization of the FUA is to be done by means of investigation (surveys and traffic counts), which gives a picture of the demand for urban freight transport services, and by means of the supply process (services, operators and infrastructures). In order to achieve this, it is necessary to collect data through surveys [36]. The research does not only apply to the infrastructure analysis, traffic count, cargo flows, etc., but also to the attitude of the stakeholders. The article presents results of analysis of attitudes of chosen groups of stakeholders in the OMG-G-S metropolis in Poland. The research results can be compared with the results obtained by seven partners of the SULPiTER project. These results prove that the respondents' distance themselves from solutions that would require them to engage in work, finance or change their strategy. Due to the representation of the sample, the results were not analyzed according to the classical division into stakeholders of urban space, but according to the size of the surveyed companies. The study revealed that larger companies revealed greater openness to change, greater awareness and greater willingness to cooperate or change strategies. Measures from the UFT area were not always perceived as advantageous. Based on the conducted research, it could be concluded that the hypothesis presented in the article was verified as positive.

However, in order to bring measures to the desired effect, it is necessary to establish a dialogue with all the stakeholders so that particular groups understand each other, and then choose such solutions that are acceptable to all groups. Such a dialogue is freight quality partnership (FQP). FQP is a tool for bringing the interested stakeholders together in order to identify: problems of each interest group regarding the movement and delivery of goods; measures to solve such problems; best practice measures and principles for action for local authorities and industry that are meant to promote eco-friendly, economic and efficient delivery of merchandise [37]. In parallel with the FQP, it is therefore necessary to conduct a study of attitudes towards selected measures, such as those presented in this paper. The study provides city policy makers with useful general guidelines for implementing sustainable measures to make the metropolis logistics more effective.

Sustainable urban logistics plans (SULPs) are designed to improve the distribution of goods in cities, make urban logistics efficient, based on the conditions of a particular city. SULP of a given city is supposed to bring the city closer to the European Commission (EC) goal to obtain $\mathrm{CO}_{2}$-free city logistics in 10 years from 2020. Urban logistics is to be efficient, rational, economical, sustainable, based on sustainable logistics measures in the field of infrastructure, technology and regulation.

By now, nine European cities of the ENCLOSE (ENergy efficiency in City LOgistics Services for small and mid-sized European Historic Towns) project (Lucca, Trondheim, Hertogenbosh, Burgos, Almada, Dundee, Alba Julia, Serres, Balchik) have already introduced their SULPs and seven other cities of the SULPiTER project (Bologna, Budapest, Brescia, Maribor, Poznan, Rijeka, Stuttgart) are in the process of introducing it. The introduction of selected resources and services leads to the optimization of the flow of goods, energy efficiency, which in turn results in the reduction of greenhouse gas emissions and local air pollution.

Policy makers should concentrate more on urban freight mobility planning in order to develop and adopt sustainable urban logistics plans-SULPs. Stakeholders are not aware of the needs and objectives of other stakeholder groups. Thus the role of the authorities is the constant broadening of awareness, pointing the advantages resulting from modern logistics solutions like cooperation on the road (load-sharing), competition on the shelf and creating FQP.

The research results are aimed at increasing the ability of city authorities to design a freight transport planning policy by matching the freight transport needs with the need to reduce its negative environmental impact. In this context, the research carried out in OMG-G-S may become the basis for the future sustainable urban logistics plan and the freight quality partnership initiative. It may also 
inspire other municipal institutions to similar initiatives. The questions and methodology adopted for analyzing research results can be used by cities preparing their SULPs.

Author Contributions: Conceptualization, data curation, funding acquisition, investigation, methodology, project administration, resources, supervision, validation, visualisation, writing —original, draft, writing—review, editing, M.M.; data curation, formal analysis, funding acquisition, investigation, methodology, project administration, validation, visualisation, writing-review, editing; R.R.; Conceptualization, investigation, writing-original, draft; M.F.

Funding: This research received no external funding

Conflicts of Interest: The authors declare no conflict of interest

\section{References}

1. Ranieri, L.; Digiesi, S.; Silvestri, B.; Roccotelli, M. A Review of Last Mile Logistics Innovations in an Externalities Cost Reduction Vision. Sustainability 2018, 10, 782. [CrossRef]

2. ICLEI. Local Governments for Sustainability. Available online: https://ecomobility.org/ecologistics (accessed on 2 January 2019).

3. Kaszubowski, D. Evaluation of urban freight transport management measures. LogForum 2012, 8, $217-229$.

4. TRIMIS. Transport Research and Innovation Monitoring and Information System. 2019. Available online: https:/trimis.ec.europa.eu/project/urban-electronic-logistics (accessed on 12 October 2019).

5. Aditjandra, P.; Zunder, T. Developing a multidimensional poly parametric typology for city logistics. In Proceedings of the 10th International Conference on City Logistics, Phuket Island, Thailand, 14-16 June 2015.

6. Perboli, G.; De Marco, A.; Perfetti, F.; Marone, M. A New Taxonomy of Smart City Projects. Transp. Res. Procedia 2014, 3, 470-478. [CrossRef]

7. Neirotti, P.; De Marco, A.; Cagliano, A.C.; Mangano, G.; Scorrano, F. Current trends in Smart City initiatives: some stylized facts. Cities 2014, 38, 25-36. [CrossRef]

8. Patier, D.; Browne, M. A methodology for the evaluation of Urban logistics innovations. Procedia Soc. Behav. Sci. 2010, 2, 6229-6241. [CrossRef]

9. Teo, J.S.E.; Taniguchi, E.; Qureshi, A.G. Evaluating city logistics measure in e-commerce with multiagent systems. Procedia Soc. Behav. Sci. 2012, 39, 349-359. [CrossRef]

10. Anand, N.; Quak, H.; Van Duin, R.; Tavasszy, L. City logistics modelling efforts: Trends and gaps-A review, The Seventh International Conference on City Logistics. Procedia Soc. Behav. Sci. 2012, 39, 101-115. [CrossRef]

11. Tamagawa, D.; Tanigucha, E.; Yamada, T. Evaluating city logistics measures using a multi-agent model. Soc. Behav. Sci. 2010, 2, 6002-6012. [CrossRef]

12. Ogden, K.W. Urban Goods Movement: A Guide to Policy and Planning; Routledge: New York, NY, USA, 1992.

13. OECD. Functional Urban Areas. Available online: http://www.oecd.org/cfe/regional-policy (accessed on 3 May 2019).

14. SULPiTER. Project Website. 2019. Available online: https://www.interreg-central.eu/Content.Node/ SULPiTER.html (accessed on 8 December 2019).

15. Ambrosino, G. Guidelines for Developing and Implementing a Sustainable Urban Logistics Plan, ENCLOSE Doc. Type/ No./Title, Deliverable D5.2: A Framework for the Definition and Implementation of Sustainable Urban Logistics Plans in Historic Small-/Mid-Size Towns Version, v. 2.0. 2015. Available online: https://www. eltis.org/sites/default/files/trainingmaterials/enclose_d5_2_sulp_methodology_final_version_0.pdf (accessed on 12 August 2019).

16. Giuliano, G. The challenges of urban freight: A research perspective. In Proceedings of the VREF Conference on Urban Freight, Gothenburg, Sweden, 17-19 October 2018.

17. Matusiewicz, M. Towards Sustainable Urban Logistics: Creating Sustainable Urban Freight Transport on the Example of a Limited Accessibility Zone in Gdansk. Sustainability 2019, 11, 3879. [CrossRef]

18. Matusiewicz, M. The argumentation for the implementation of urban consolidation center for the Old Town in Gdansk as an indication of sustainable urban freight logistics. Transp. Econ. Logist. 2018, 69, 63-71. [CrossRef]

19. Naskręt, M. Rośnie Liczba Mieszkańców Trójmiasta, Portal Trojmiasto.pl. Available online: https://www. trojmiasto.pl/wiadomosci/Rosnie-liczba-mieszkancow-Trojmiasta-n129832.html (accessed on 24 February 2019). 
20. Michalski, L.; Jamroz, K.; Grzelec, K.; Grulkowski, S.; Kaszubowski, D.; Okraszewska, R.; Birr, K.; Kustra, W. Strategia Transportu i Mobilności Obszaru Metropolitalnego Gdansk—Gdynia Sopot do Roku 2030, Załącznik nr 5, Analizy możliwości Rozwoju Systemu Transportowego Obszaru Metropolitalnego. Available online: https://www.metropoliagdansk.pl/upload/files/STIM_ZIT_Strategia-VI\%205_2015-10-9_2(1).pdf (accessed on 10 April 2018).

21. Szatanowska, A.; Kotlewska, K.; Licznerska, M.; Samociuk, K. Trackingowe badanie świadomości i zachowań ekologicznych mieszkańców Polski, Ministerstwo Środowiska. 2018. Available online: https://www.mos.gov.pl/fileadmin/user_upload/mos/srodowisko/edukacja/Swiadomosc_ekologiczna_ Polakow_2018_raport_graficzny_fin_pdf.pdf (accessed on 10 December 2018).

22. Oliveira, G.F.; Oliveira, L.K. Stakeholders' perceptions of city logistics: An exploratory study in Brazil. Transp. Res. Procedia 2016, 12, 339-347. [CrossRef]

23. Letnik, T.; Luppino, G.; Bardi, A. Urban freight transport policies and measures implemented in strategic documents of European cities-A review. In European Review of Regional Logistics; ENLOCC: Sttutgart, Germany, 2019; Volume 2.

24. Kaszubowski, D. Recommendations for Urban Freight Policy Development in Gdynia. Transp. Res. Procedia 2016, 12, 886-899. [CrossRef]

25. Kaszubowski, D. Urban Freight Transport Demand Modelling and Data Availability Constraints. In Advanced Solutions of Transport Systems for Growing Mobility; Sierpiński, G., Ed.; Advances in Intelligent Systems and Computing; Springer: Cham, Switzerland, 2018.

26. Kaszubowski, D.; Oskarbski, J. Applying a Mesoscopic Transport Model to Analyse the Effects of Urban Freight Regulatory Measures on Transport Emissions-An Assessment. Sustainability 2018, 10, 2515.

27. Kaszubowski, D. A Method for the Evaluation of Urban Freight Transport Models as a Tool for Improving the Delivery of Sustainable Urban Transport Policy. Sustainability 2019, 11, 1535. [CrossRef]

28. Iwan, S.; Kijewska, K.; Lemke, J. Analysis of Parcel Lockers' Efficiency as the Last Mile Delivery Solution-The Results of the Research in Poland. Transp. Res. Procedia 2016, 12, 644-655. [CrossRef]

29. Iwan, S.; Kijewska, K.; Johansen, B.G.; Eidhammer, O.; Majewski, K.; Konicki, W.; Thompson, R.G. Analysis of the environmental impacts of unloading bays based on cellular automata simulation. Transp. Res. Part D Transp. Environ. 2017, 61, 104-117. [CrossRef]

30. Kiba-Janiak, M.; Cheba, K. Information system for city logistics. The case of Poland. Transp. Res. Procedia 2019, 39, 160-169. [CrossRef]

31. Kiba-Janiak, M. EU cities' potentials for formulation and implementation of sustainable urban freight transport strategic plans. Transp. Res. Procedia 2019, 39, 150-159. [CrossRef]

32. Kijewska, K.; Krupa, M.; Iwan, S. Risk assessment of international urban logistics projects on the Low Carbon Logistics example. Autobusy 2019, 20, 445-451. [CrossRef]

33. Witkowski, J.; Kiba-Janiak, M. The Role of Local Governments in the Development of City Logistics. Procedia Soc. Behav. Sci. 2014, 125, 373-385. [CrossRef]

34. Nürnberg, M.; Iwan, S. Application of Telematics Solutions for Improvement the Availability of Electric Vehicles Charging Stations. In Proceedings of the 19th International Conference on Transport System Telematics, Jaworze, Poland, 27 February-2 March 2019.

35. Foltyński, M. New challenges for transport systems beyond 2020—SULPiTER project. In Proceedings of the 3rd International Conference Green Cities 2018-Green Logistics for Greener Cities, Szczecin, Poland, 13-14 September 2018.

36. Foltyński, M. Sustainable Urban Logistics Plan-Current situation of the city of Poznań. Transp. Res. Procedia 2019, 39, 42-53. [CrossRef]

37. Rubini, L.; Dell Lucia, L. Governance and the stakeholders' engagement in city logistics: the SULPiTER methodology and the Bologna application, EURO Mini Conference on "Advances in FreightTransportation and Logistics. Transp. Res. Procedia 2018, 30, 255-264. [CrossRef]

(C) 2019 by the authors. Licensee MDPI, Basel, Switzerland. This article is an open access article distributed under the terms and conditions of the Creative Commons Attribution (CC BY) license (http://creativecommons.org/licenses/by/4.0/). 